ИЗВЕСТИЯ АКАДЕМИИ НАУК ЭСТОНСКОИ ССР. ТОМ 31 ГЕОЛОГИЯ. 1982, № 4

\title{
НОВЫЕ ВИДЫ ХИТИНОЗОЙ РОДОВ ANCYRO-, GOTLANDO- И SPHAEROCHITINA ИЗ ВЕНЛОКА ЭСТОНИИ
}

Настоящая статья относится к серии работ по таксономии и зональному распределению венлокских хитинозой Эстонии (Нестор, 1982а, б, в). Описанные в данной работе виды происходят из самых нижних и верхних слоев венлока Әстонии. В низах венлока, в слоях, соответствующих граптолитовой зоне C. murchisoni (Кальо, 1970), присутствует разнообразный комплекс хитинозой (Нестор, 1982б,в), включающий такие редкие виды, как Ancyrochitina magna, Gotlandochitina? angusta, G. magnifica, G. ruhnuensis. Распространение этих видов в разрезах Эстонии опраничено, а южнее (скважины Вентспилс, Колка) и на о-ве Готланд они вообще не найдены (Laufeld, 1974, 1979). Возможно, что исчезновение комплекса этих видов связано с развитием венлокской транспрессии, проявляющейся в расширении ареала граптолитовых отложений в Палеобалтийском бассейне и достигшей своего макси-
мума во время существования зоны riccartonensis.

Один из описанных видов - Sphaerochitina indecora - приурочен к верхам венлока, грубо соответствующим зоне nassa (Нестор, 1982б).

За полезные советы при подготовке рукописи к печати автор признателен Р. Мяннилю и Х. Нестору. Микрофотопрафии выполнены сотрудником института Е: Климовым на сканирующем электронном микроскопе фирмы «Акаси» (Япония).

Материал хранится в Институте геологии АН ЭССР.

Род Ancyrochitina Eisenack, 1955

Ancyrochitina magna sp. $\mathrm{n}$.

Табл. I, фиг. $1-2$

Н аз вание вида от magna (лат.) - большой.

Г олотип. Ch 115/1398, скв. Варбла, гл. 135,1 м, яаниский горизонт. Ди агноз. Везикула цилиндро-коническая, с выпуклым основанием. Широко закругленный базалыный край снабжен 5-6 полыми, проксимально расширяющимися отростками. Шейка носит маленькие треугольные шипы.

О пи сание. Шейка составляет обычно больше половины общей длины везикулы. Флексура хорошо развита, плечо отсутствует. Основание везикулы сильновыпуклое, лишено базального края. Отростки треугольной формы, плоские, с широким основанием и утончающейся верхушкой, обычно изогнутые в аборалыном направлении. Длина, ширина и внешняя поверхность их неравномерные.

Маленькие треугольные шипы на шейке (обычно их 2-4) ориентированы в направлении продольной оси везикулы. Устьевой край мелкобахромчатый. Поверхность везикулы гладкая до редко-гранулированной. 
Р азме ры (в микронах): длина $160-210$ (у голотипа 190), наибольшая ширина камеры 70-100 (у голотипа 100), наименьшая ширина шейки 25-40 (у голотипа 30 ), длина отростков $15-50$, наибольшая ширина отростков $15-35$.

Сравнение и 3 а меч ания. Ancyrochitina magna встречается совместно с $A$. primitiva (Eisenack, 1964) и $A$. cf. pachyderma (Laufeld, 1974); отличается от них величиной (A. magna длиннее) и формой отростков и наличием шипов на шейке, а также выпуклым основанием везикулы.

Следует отметить, что вместе с $A$. magna местами (скв. Рунху, гл. 455,05 м) встречаются еще близкие к нему формы, у которых верхушки отростков обычно раздванваются.

Р аспространение и м тери ал. Редкий вид с опраниченным ареалом распространения. Встречается в скв. Варбла, гл. 135,1 м и в скв. Рухну, гл. 454 м. Всего в коллекции около 25 экземпляров.

\section{Род Gotlandochitina Laufeld, 1974 \\ Gotlandochitina? angusta sp. n.}

Табл. I, фиг. 3

Н а звани е вида указывает на узкую форму камеры, а также на ограниченное распространение его.

Голоти п. Ch 111/1736, скв. Рухну, гл. 454 м, яаниский горизонт.

Д и агноз. Цилиндро-сферическая везикула лишена базального края. Шипы различной формы и величины расположены неправилыными рядами. Внешняя поверхность везикулы бугорчатая.

О п и с ан и е. Камера составляет около половины всей длины везикулы. Флексура слабая и плечо отсутствует. Ряды шипов часто неясные и расположены редко. Шипы различной формы, часто парусовидные, по продольной оси везикулы срастающиеся. Устье ровное. Внешняя поверхность везикулы неравномерно-бугорчатая.

Р азмеры голотипа (в микронах): длина 290, наибольшая ширина 115 , ширина шейки 45 , наибольшая длина шипов $30-35$.

С р а внен и е и з а м ч а н и. По внешней форме данный вид похож на Angochitina longicollis (Eisenack, 1959), вместе с которым он и встречается. Отличается от него типом орнаментации, формой и длиной шипов. Родовая принадлежность нового вида еще не совсем ясна, так как по орнаментации (ряды шипов) он сходен с Gotlandochitina, a по внешей форме - c Angochitina.

Р аспространение и м тери лл. Один экземпляр хорошей сохранности, скв. Рухну, гл. 454 м.

\section{Gotlandochitina magnifica sp. n.}

Табл. І, фиг. 4; Табл. II, фиг. 1

Название вида magnifica (лат.) - великолепный, роскошный характеризует богатую красивую орнаментацию из разветвляющихся шипов.

Голотип. Ch 113/1736, скв. Рухну, гл. 454 м, яаниский горизонт.

Ди агноз. Везикула цилиндро-сферическая, снабжена длинными, 
2 -5 раз разветвляющимися шипами. Шипы расположены в $7-8$ рядов на аборальной половине камеры и на оральной половине шейки. Середина основания лишена шипов.

О пи сани е. Соотношение камеры и шейки в среднем 1:1. Флексура и плечо широко закругленные. Камера сферическая, без базального края. Шипы расположены более или менее правильно, в среднем по три шипа в ряду. Середина основания и оральная половина камеры лишены шипсв. Отростковидные шипы имеют длинную неразветвляющуюся проксимальную и 2-5 раз разветвляющуюся дистальную части. На шейке расположены тонкие, неправильно разветвляющиеся шипы. Длина их уменьшается в направление бахромчатого устья.

Р а з меры (в микронах): длина (excl.) 140-225 (у голотипа 200), наибольшая ширина $65-85$ (у голотипа 80 ), ширина шейки $25-40$, наибольшая длина шинов 55 .

C. равнение и 3 а меч ания. По внешней форме Gotlandochitina magnifica похож на G. villosa (Laufeld, 1974), но отличается от него более крупными размерами везикулы и длинными, сильно разветвляющимися отростковидными шипами.

Распространение. G. magnifica встречается в нижнем венлоке, в узком стратиграфическом интервале. Ассоциируется с Angochitina longicollis в низах яаниского горизонта. В скв. Рухну, гл. 454-456,3 м. М а тери ал. Более 50 экземпляров.

\section{Gotlandochitina ruhnuensis sp. n.}

Табл. II, фиг. $2-3$

Название вида от скважины на о-ве Рухну, откуда происходит голотип.

Г ол о тип. Ch 183/1734, скв. Рухну, гл. 457,4 м, яаниский горизонт.

Д и а г о з. Везикула цилиндро-коническая, с плоским или слабовыпуклым основанием, обладает орнаментацией из тонких шипов, расположенных неясными рядами на камере и шейке.

О пис ани е.. Шейка составляет обычно около половины всей длины везикулы. Флексура развита слабее или сильнее, плечо отсутствует. Шипы покрывают всю поверхность везикулы, но они более длинные и расположены чаще на аборальной половине камеры. На основании и в оральной части шейки шипов меньше и они короче. Шипы тонкие, изменчивые по форме, иногда разделяющиеся в своей дистальной или проксимальной части, иногда срастающиеся в основании по продольной оси везикулы. Устьевой край мелкобахромчатый. Внешняя поверхность везикулы мелкогранулированная.

Р а з меры (в микронах): длина 135-195 (у голотипа 165), наибольшая ширина $55-75$ (у голотипа 70), максимальная длина шипов 20.

С равнение и замечания. Gotlandochitina ruhnuensis отличается

\section{ТАБЛИЦА I}

Фиг. 1-2. Ancyrochitina magna sp. n., скв. Варбла, гл. 135,1 м, $\mathrm{J}_{1} .1-$ голотип Ch $115 / 1398,1 a-\times 310,16-\times 1360 ; 2-$ экз. Ch $185 / 1398, \times 310$.

Фиг. 3. Gotlandochitina ? angusta sp. п., голотип $\mathrm{Ch} 111 / 1736$, скв. Рухну, гл. 454 м, $\mathrm{J}_{1} ; 3 a-\times 250,36-\times 1360$.

Фиг. 4. Gotlandochitina magnifica sp. п., голотип Ch 113/1736, скв. Рухну, гл. 454 м, $\mathrm{J}_{1} ; 4 a-\times 310,46-\times 910$. 
ТАБЛИЦА 1
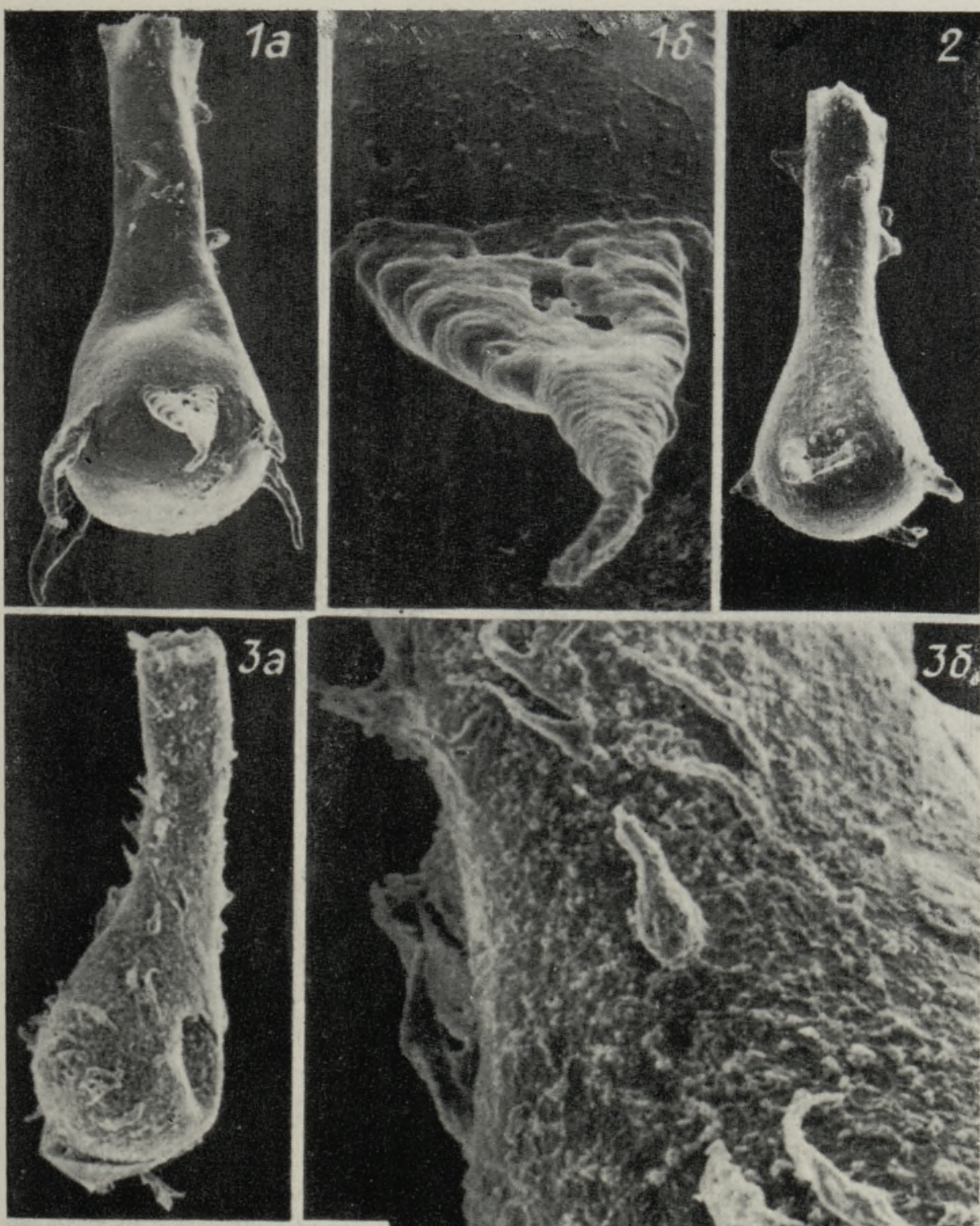

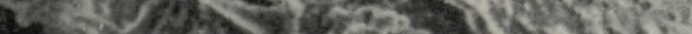

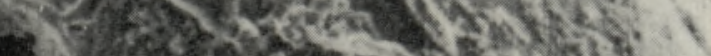

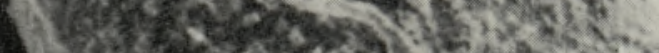

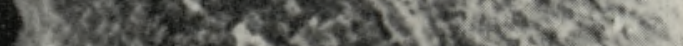
F.

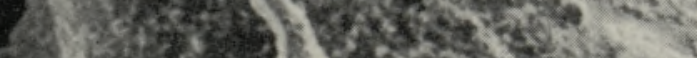
ros

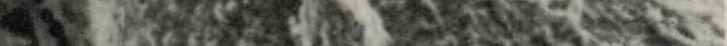

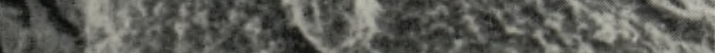

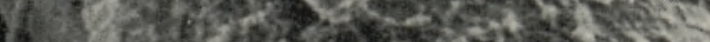

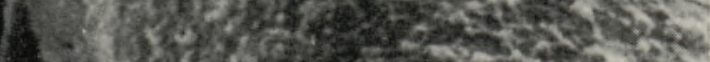

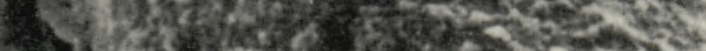

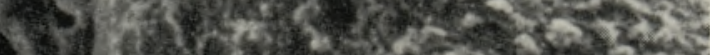

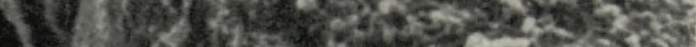

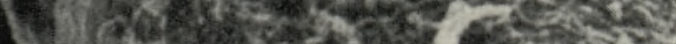

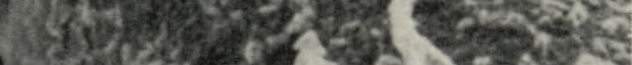

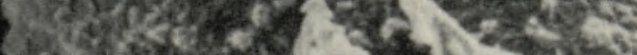
bow

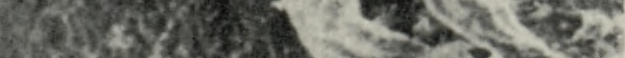
(1) 

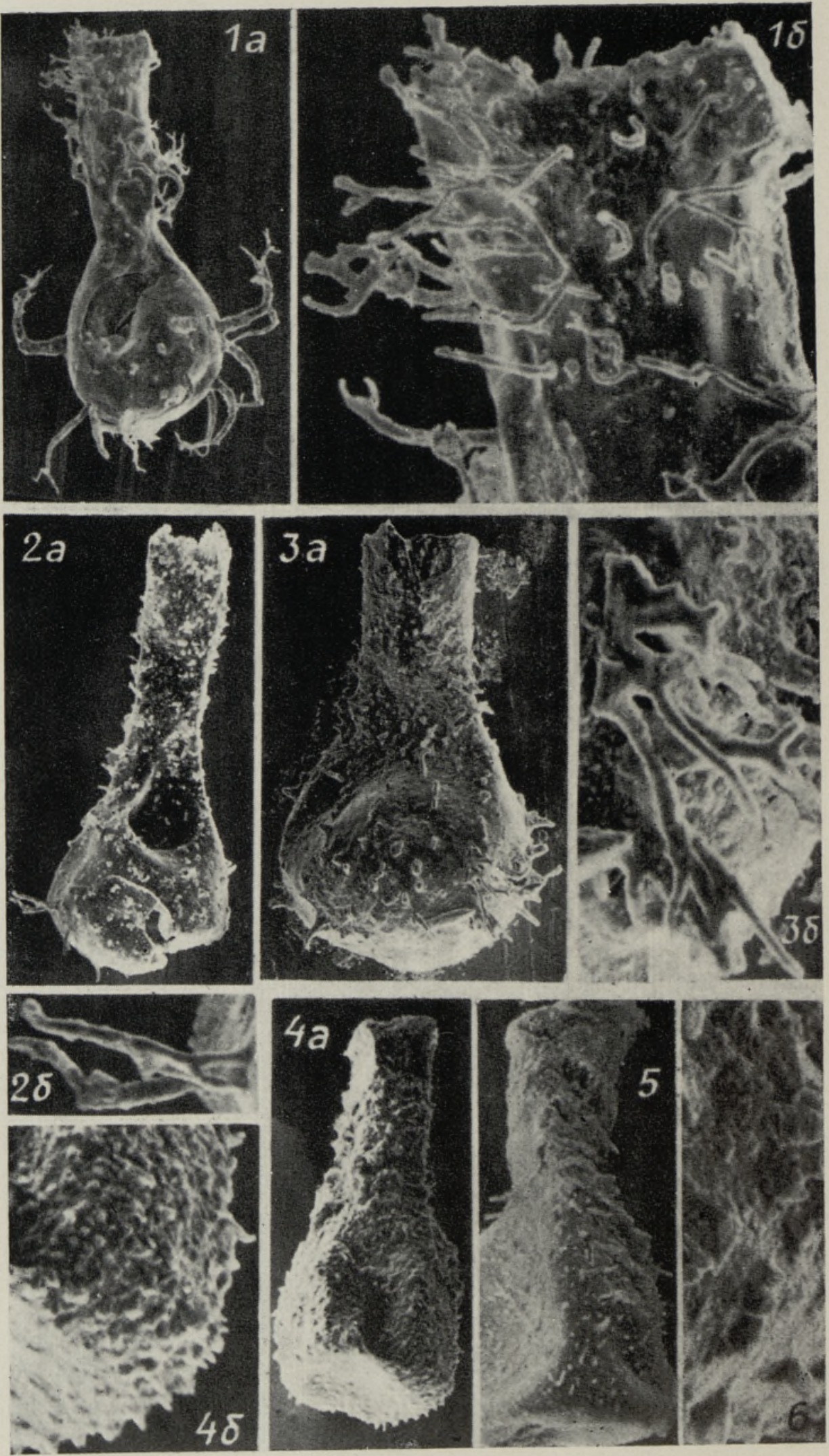
от G. corniculata (Laufeld, 1974) более тонкой и густой орнаментацией, а также формой шипов. Кроме того, у $G$. corniculata основание лишено шипов. G. martinssoni (Laufeld, 1974) и G. militaris (Laufeld, 1974) имеют сферическую камеру, шипы расположены правильными рядами и отличаются формой.

Р аспространение. Встречается в низах яаниского горизонта, но в разрезе скв. Рухну найден и в верхах адавереского горизонта: скв. Рухну, гл. 454-463,2 м; скв. Варбла, гл. 132,5-137,35 м; скв. Кирикукюла, гл. 6,30 м; скв. Пулли II, гл. 25,3-28,3 м; скв. Тылла, гл. 126,10$40 \mathrm{M}$.

Матери ал около 60 экземпляров.

Род Sphaerochitina Eisenack, 1955

Sphaerochitina indecora sp. $\mathrm{n}$.

Табл. II, фиг. $4-5$

Н азвание вида indecora (лат.) - некрасивый - указывает на грубую неравномерную орнаментацию везикулы.

Голоти п. Ch 164/650, скв. Охесааре, гл. 169,5 м, яагарахуский горизонт,

Д и агноз. Везикула цилиндро-субсферическая до конической, с закругленным или незаметным базальным краем. Внешняя поверхность камеры и шейки неравномерно покрыта массивными тупоконечными и более тонкими остроконечными шипами.

О писани е. Внешняя форма камеры изменчивая. Чаще встречаются экземпляры с субконической камерой, с больше или меньше выпуклыми боковыми стенками и с закругленным, но ясным базальным краем. Флексура и плечо в разной степени развиты. Орнаментация покрывает всю поверхность везикулы, она мелче на основании и в устьевой части шейки. Неправильные по форме шипы расположены неравномерно. Шипы обычно простые, конические, неодинаковой длины, иногда более массивные, с тупым концом. Внешняя поверхность везикулы неравномерно-бугорчатая или гранулированная.

Р а з м еры (в микронах): длина 100-160, наибольшая ширина камеры $50-70$, ширина шейки 25-30, максимальная длина шипов 5-6.

С равнение и замеч ания. Sphaerochitina indecora близок к S. concava (Laufeld, 1974), но у S. indecora боковые стенки везикулы более прямые, менее выпуклые, шипы грубее, расположены реже и неравномернее.

От S. impia (Laufeld, 1974) данный вид отличается в основном более длинными, редкорасположенными шипами.

Большинство имеющихся экземпляров данного вида плохо сохранилось, частично разломано.

\section{ТАБЛИЦА ІІ}

Фиг. 1. Gotlandochitina magnifica sp. п., экз. Ch 184/1736, скв. Рухну, гл. 454 м, $\mathrm{J}_{1} ; 1 a-\times 310,16-\times 1360$.

Фиг. 2-3. Gotlandochitina ruhnuensis sp. n., $\mathrm{J}_{1} .2$ - голотип Ch 183/1734, скв. Рухну, гл. 457,4 м, $2 a-\times 440,26-\times 2330 ; 3-$ экз. Ch 912/9188, скв. Тылла, гл. $126,10-40 \mathrm{M}, 3 a-\times 440,36-\times 2040$.

Фиг. 4-6. Sphaerochitina indecora sp. п. Ј⿰氵 4 - голотип Ch 164/650, скв. Охесаape, гл. 169,5 м, $4 a-\times 460,46-\times 1360.5-$ экз. Сh 186/1784, скв. Рухну, гл, 293,7 м, ×660. 6 - экз. Ch 165/1876 (деталь), скв. Рухну, гл. 290 м, ×2040. 
Р а п ространение. Верхи яагарахуского горизонта в разрезах скв. Oxесаape, гл. 145-172 м, скв. Рухну, гл. 269-309 м, скв. Икла, гл. $185-188$ м, скв. Колка, гл. $409-430$ м.

Ма тери ал около 20 экземпляров.

\section{ЛИТЕРА Т У Р А}

К альо Д. Граптолиты. - В кн.: Силур Эстонин. Таллин, 1970, 179-185.

Н ест о В. Новые хитинозои рода Conochitina из венлока Эстонии. - Изв. АН ЭССР. Геол., 1982a, 31, 105-111.

Нестор В. Зональное распределение хитинозой в яаниском горизонте (венлок Эстонии) и проблема его границ. - В кн.: Стратиграфия древнепалеозойских отложений Прибалтики. Таллин, 19826, (в печати).

Н ест о р В. Зональные комплексы хитинозой венлока Эстонии. - В кн.: Сообщества и биозоны в силуре Прибалтики. Таллин, 1982в, (в печати).

E is enack, A. Neotypen baltischer Silur-Chitinozoen und neue Arten. - N. Jb. Geol. Pal. Abh. 1959, Bd. 108, 1-20. .

E is en a ck, A. Mikrofossilien aus dem Silur Gotlands. Chitinozoen. - N. Jb. Geol. Pal. Abh. 1964, Bd. 120, 308-342.

L a ufeld, S. Silurian Chitinozoa from Gotland. - Fossils and Strata, 1974, 5.

L a uf eld, S. Chitinozoans. - In: Lower Wenlock faunal and flonal dynamics. Vattenfallet section, Gotland, Uppsala, 1979, 70-76.
Институт геологии
Академии наук Эстонской ССР
Поступила в редакцию
$31 /$ III 1982

Viiu NESTOR

\section{UUED KITINOZOADE LIIGID PEREKONDADEST ANCYRO-, GOTLANDO- JA SPHAEROCHITINA EESTI UENLOKIST}

Artiklis on kirjeldatud viit uut kitinozoade liiki ja iseloomustatud nende levikut Eesti uenloki läbilöikes.

Viiu NESTOR

\section{NEW CHITINOZOANS OF THE GENERA ANCYRO-, GOTLANDO-, AND SPHAEROCHITINA FROM THE WENLOCKIAN OF ESTONIA}

The present paper is a part of the results of the author's studies on the taxonomy and zonal distribution of Estonian Wenlockian chitinozoans (Нестор, 1982a, б, в). Five new species are described, out of which Ancyrochitina magna, Gotlandochitina angusta, $G$. magnifica, $G$. ruhnuensis occur in the Lower-Wenlockian rocks of the Jaani Stage, in the interval corresponding to the graptolite C. murchisoni Zone. Sphaerochitina indecora is present in the Upper Wenlockian Jaagarahu Stage of the SouthEstonian region, in the beds that mainly correspond to the $G$. nassa Zone.

\section{Ancyrochitina magna sp. $\mathrm{n}$.}

A big Ancyrochitina species with cylindroconical vesicle and convex base. Broadly rounded basal edge carries 5-6 stout, distally tapering appendices. The neck is provided with short triangular spines with the base elongated in the longitudinal direction. The vesicle wall is finely granulated.

\section{Gotlandochitina ? angusta $\mathrm{sp} . \mathrm{n}$.}

Cylindrosphaerical vesicle lacking basal edge. The vesicle wall is provided with irregular spines, arranged more or less conspicuously in longitudinal rows. Usually spines 
are flattened with elongated bases oriented longitudinally towards the vesicle axes. The proximal parts of spines are sometimes fused, forming sail-like ornamentation. The vesicle wall between the spines is verrucated.

\section{Gotlandochitina magnifica sp. $\mathrm{n}$.}

Cylindrosphaerical vesicle lacking basal edge, provided with long branching spines arranged in $7-8$ longitudinal rows in the aboral part of the chamber and in the oral part of the neck. Spines are lacking in the central part of the base. The spines have a long unbranched proximal part and $2-5$ times branching distal part. Irregularly branching spines on the neck decrease in size towards the aperture.

\section{Gotlandochitina ruhnuensis sp. n.}

Cylindroconical vesicle with flat or slightly convex base, covered by ornamentation of thin spines which are arranged in more or less conspicuous rows. They are best developed on the chamber wall and less densely distributed on the neck and base. The spines are variable - either simple or with coalescent bases, elongated in longitudinal direction, branching distally. The vesicle wall between the spines is finely granulated.

\section{Sphaerochitina indecora sp. n.}

Cylindro-subsphaerical to cylindroconical vesicle with a broadly rounded or conspicuous basal edge. The vesicle wall is covered by uneven. ornamentation of small massive blunt spines, thinner pointed spines and wide verrucae. The size and density of spines decrease toward the aperture and aboral base. 